\title{
The Impact of Criminal Code Training on Eyewitness Identification Accuracy
}

\author{
Michael Storozuk ${ }^{1}$, Paul Dupuis ${ }^{2}$ \\ ${ }^{1}$ Department of Criminology, University of Toronto, Toronto, Canada \\ ${ }^{2}$ Department of Psychology, Algoma University, Sault Ste Marie, Canada \\ Email: paul.dupuis@algomau.ca
}

Received August $16^{\text {th }}$, 2013; revised September 14 $4^{\text {th }}, 2013$; accepted October $13^{\text {th }}, 2013$

\begin{abstract}
Copyright ( $\odot 2013$ Michael Storozuk, Paul Dupuis. This is an open access article distributed under the Creative Commons Attribution License, which permits unrestricted use, distribution, and reproduction in any medium, provided the original work is properly cited. In accordance of the Creative Commons Attribution License all Copyrights (c) 2013 are reserved for SCIRP and the owner of the intellectual property Michael Storozuk, Paul Dupuis. All Copyright @ 2013 are guarded by law and by SCIRP as a guardian.
\end{abstract}

\begin{abstract}
Eyewitness identification accuracy of offenders (persons who committed a crime) is generally unreliable. In this study, we implemented a training approach to examine the impact of a brief criminal law training session on the identification accuracy of eyewitnesses viewing a simulated violent altercation between two males. Participants provided with prior training on how to appropriately apply specific criminal law definitions relevant to a violent altercation (assault and self-defense provisions) were more accurate in their identifications of the offender when compared to participants provided with irrelevant training (a riot and the unlawful assembly of a riot), and participants provided with no training, when observing the same violent altercation. Potential implications and limitations are discussed.
\end{abstract}

Keywords: Eyewitness Identification; Criminal Law; Training

\section{Introduction}

One of the most prevalent findings in the forensic psychology literature is that eyewitness identification is often unreliable and inaccurate (Leippe, Eisenstandt, \& Rauch, 2009; Webber \& Perfect, 2012). This finding is largely stable across a variety of crime types (Wells \& Olson, 2003; Clark, Marshall, \& Rosenthal, 2009) as well as across a variety of lineup procedures and techniques (see Steblay, Dysart, \& Wells, 2011; Wells \& Olson, 2003 for reviews). As many of these estimator and system variables have been shown to contribute to unreliable and inaccurate eyewitness memory, we were interested in assessing eyewitness identification accuracy from a different perspective, a training perspective. Specifically, we were interested in examining whether or not training in certain sections of the Criminal Code would impact eyewitness identification accuracy for a dyadic violent crime altercation, a social interaction that leads to the exchange of criminal violence between two people (Athens, 2005).

Eyewitness offender identification accuracy for dyadic violent crime altercations can be particularly unreliable, in large part because the processing of information about the offender can be difficult for an eyewitness (Deffenbacher, Bornstein, Penrod, \& McGorty, 2004; Marsh \& Greenberg, 2006). With both individuals (i.e., offender and victim) of a dyadic violent crime altercation exchanging acts of criminal violence (Athens, 1997; Guerette \& Santana, 2010), there is a potential decrease in the amount of attention an eyewitness can devote to the offender's characteristics. A lack of attention may hinder the eyewitness's memory for the offender's characteristics, and consequently negatively impact identification accuracy in the event that they are later questioned by the police (Tuckey \& Brewer, 2003; Hellman, Echterhoff, Hopietz, Niemeier, \& Memon, 2011).

Our intention in this study is to provide an empirical approach that can be offered as a potential starting point for future research. This approach involves training in specific aspects of criminal law. Criminal laws are in the public domain and the average citizen is expected to have some knowledge of these laws. For example, one of the main purposes of criminal laws (e.g. the Canadian Criminal Code) is to inform the public of the actions they are criminally prohibited from performing (Hermida, 2011). An implication for an eyewitness is that if they notice that an incident involves a crime and can determine which behaviors in a given incident are criminal, their attention can be devoted more appropriately to relevant details of the incident (e.g. the offender). However, the assumption that the average person is knowledgeable enough about criminal law to apply this to an incident involving criminal behavior is tenuous.

Therefore, we investigated whether training eyewitnesses about how to appropriately apply the content within a given violent crime definition (how to identify the behaviors implicated in the criminal act) and a given justification (how to identify who is and who is not justified in committing such a criminal act) would increase their ability to accurately identify the offender of a dyadic violent altercation, when compared to eyewitnesses who did not receive such training. We hypothesized that eyewitness identification of the offender would be more accurate for participants in the specific-training group than for participants in the nonspecific-training group and the control group. Our hypothesis was based on the assumption that involvement in the specific-training group would disambiguate 
the dyadic violent crime altercation in regards to discerning between the offender and victim. We thought that this could increase participants' awareness of the offender's characteristics when they observed the altercation, increase participants' memory for the offender, and therefore result in more accurate eyewitness identifications.

\section{Methods}

We presented participants (78 introductory psychology students from Algoma University) with a fifty-eight second videotaped violent altercation depicting two males committing criminal violence as per the assault definition in the Criminal Code (see section 265 of Criminal Code, 1985). As per the self-defence definition in the Criminal Code (see section 35 of Criminal Code, 1985), one of the males was justified in self-defence (i.e., the victim) and the other was not (i.e., the offender). Between five and seven days prior to viewing the violent altercation and performing the eyewitness identification procedure, participants randomly received one of three forms of training. Participants were either trained how to appropriately apply the assault and self-defence definitions to a hypothetical case (the specific-training group), how to appropriately apply an irrelevant Criminal Code definition (riot and unlawful assembly of a riot) to a hypothetical case (the non-specific training group), or received no training (the control group). Following the training and the presentation of the videotaped violent altercation, participants were all presented with a six person, target present, simultaneous lineup and asked to identify the person from the video who committed assault or to indicate that the offender was not present. The lineup consisted of the offender and five foils (known innocents not present in the video). The victim from the video never appeared in the lineup.

\section{Results}

The impact of group training (i.e., specific-training group, non-specific training group, and control group) on eyewitness identification accuracy of the offender was analyzed using a One-Way ANOVA. All statistical analyses were conducted at the $p<0.05$ significance level. There was a statistically significant main effect for the impact of group training. Results indicated that eyewitness identification of the offender was most accurate for participants in the specific-training group ( $M$ $=1.30)$, less accurate for participants in the control group $(M=$ $1.60)$, and least accurate for participants in the non-specific training group $(M=1.78)(F(2,75)=7.34, p<0.01)$. Post-hoc analyses revealed that eyewitness identification was more accurate for participants in the specific-training group than for participants in the non-specific training group $(p<0.01)$ or the control group $(p<0.05)$. The identification accuracy of participants in the control group did not differ from those in the non-specific training group $(p>0.05)$.

\section{Discussion}

Research shows that eyewitnesses are generally unreliable when it comes to identifying an offender from a crime they observed (Wells \& Olson, 2003; Webber \& Perfect, 2012). Consequently, a long standing problem faced by researchers has been the question of how to improve eyewitness identification accuracy. Researchers have explored numerous variables to gauge the impact on eyewitness identification accuracy with generally limited success (see Wells \& Olson, 2003).

Ambiguity over explicitly distinguishing between the offender and victim may negatively impact an eyewitness's information processing of the offender's characteristics when they are observing a dyadic violent altercation, thereby potentially negatively impacting an eyewitness's identification accuracy (e.g., Tuckey \& Brewer, 2003; Hellman, Echterhoff, Hopietz, Niemeier, \& Memon, 2011). We thought that a potential approach to improving eyewitness offender identification in regard to this ambiguity issue would be to provide eyewitnesses with prior training on how to appropriately apply Criminal Code definitions that are directly relevant to the behavior of the individuals (i.e., offender and victim) who are party to a given dyadic violent altercation.

The experimental results supported our hypothesis that participants given specific training on relevant Criminal Code sections would be more accurate in identifying the offender. Results indicated that eyewitness identification was more accurate for participants in the specific-training group than for participants in the non-specific training and no training groups. At face value, this finding could imply that providing laypersons with Criminal Code training may be a useful approach to take toward improving eyewitness identification accuracy of dyadic violent altercations. Further research is needed to determine if specific training of this sort consistently leads to higher identification accuracy as well as how this might be occurring. Perhaps the attention and focus of eyewitnesses were directed more appropriately when given specific training due to a decrease in the ambiguity of the incident. This can only be implied from our findings and further empirical research is needed to directly address this potential explanation. Further research could also explore whether this type of criminal law training could be successful for other types of crimes. For example, would specific training in criminal negligence promote accurate eyewitness identifications for participants exposed to a simulated case involving multiple people only one of which was criminally negligible? Additionally, introductory psychology students do not necessarily represent the average citizen well. Would conducting similar research within a broader participant pool find similar results? Future research could also examine whether having different gender or ethnicity combinations of offenders and victims would result in similar findings? Our data cannot speak to these questions, but perhaps can encourage more directed attempts to address these and other related issues.

\section{REFERENCES}

Athens, L. (1997). Violent criminal acts and actors revisited. Chicago: University of Illinois Press.

Athens, L. (2005). Violent encounters: Violent engagements, skirmishes, and tiffs. Journal of Contemporary Ethnography, 34, 631-678. http://dx.doi.org/10.1177/0891241605280570

Clark, S. E., Marshall, T.E., \& Rosenthal, R. (2009). Lineup administrator influences on eyewitness identification decisions. Journal of Experimental Psychology: Applied, 15, 63-75. http://dx.doi.org/10.1037/a0015185

Criminal Code, R.S.C. C-46 (1985).

laws-lois.justice.gc.ca/eng/acts/C-46/

Deffenbacher, K. A., Bornstein, B. H., Penrod, S. D., \& McGorty, E. K. (2004). A meta-analytic review of eyewitness memory. Law and Human Behavior, 28, 687-706.

http://dx.doi.org/10.1007/s10979-004-0565-x 
Guerette, R. T., \& Santana, S. A. (2010). Explaining victim self-protective behavior effects on crime incident outcomes: A test of opportunity theory. Crime \& Delinquency, 56, 198-226.

http://dx.doi.org/10.1177/0011128707311644

Hellman, J. H., Echterhoff, G., Kopietz, R., Niemeier, S., \& Memon, A. (2011). Talking about visually perceived events: Communication effects on eyewitness memory. European Journal of Social Psychology, 41, 658-671.

http://dx.doi.org/10.1002/ejsp.796

Hermida, J. (2011). Criminal law. The Netherlands: Kluwe Law International.

Leippe, M. R., Eisenstandt, D., \& Rauch, S. M (2009). Cueingconfidence in eyewitness identifications: Influence of biased lineup instructions and pre-identification memory feedback under varying lineup condition. Law and Human Behavior, 33, 194-212.

http://dx.doi.org/10.1007/s10979-008-9135-y

Marsh, D. P., \& Greenberg, M. S. (2006). The influence of eyewitness similarity to a crime victim and victim culpability on eyewitness recall. Applied Psychology in Criminal Justice, 2, 43-56.

Steblay, N. K., Dysart, J. E., \& Wells, G. L. (2011). Seventy-two tests of the sequential lineup superiority effect: A meta-analytic analysis and policy discussion. Psychology, Public Policy, and Law, 17, 99139. http://dx.doi.org/10.1037/a0021650

Tuckey, M. R., \& Brewer, N. (2003). The influence of schemas, stimulus ambiguity, and interview schedule on eye witness memory over time. Journal of Experimental Psychology, 9, 101-118.

Webber, N., \& Perfect, T. J. (2012). Improving eyewitness identification accuracy by screening out those who say they don't know. Law and Human Behavior, 36, 28-36.

http://dx.doi.org/10.1037/h0093976

Wells, G. L., \& Olson, E. A. (2003). Eyewitness testimony. Annual Review of Psychology, 54, 277-295.

http://dx.doi.org/10.1146/annurev.psych.54.101601.145028 